\title{
Rethinking Approach to Environmental Protection in View of Ancient Indian Wisdom
}

\author{
K. Ratnabali* \\ Assistant Professor, Faculty of Law, University of Delhi, Delhi, India
}

DOI: $10.36348 /$ sijlcj.2020.v03i11.011

| Received: 05.11.2020 | Accepted: 14.11.2020 | Published: 19.11.2020

*Corresponding author: K. Ratnabali

\section{Abstract}

Perceptible improvement in the quality of air and water during COVID-19 lockdown has taught humanity several lessons and brought realization which might otherwise have been missed or taken several experiments to come to it. This study is aimed at understanding whether our approach towards holistic environmental protection needs rethinking by appropriate positioning of man as a species in the context of the biosphere and commensurate responsibility he has towards it. The technique used for the study is doctrinal research which shall take into account available primary resources, such as report as well as secondary resources, such as articles and books. The study focuses on the ancient wisdom available in the Hindu philosophies and literature in order to understand the relation between man, other living organisms, plants as well as the abiotic components of the earth. The study has shown that humans, by being at the top of the evolutionary ladder, has seeming dominance over the environ, and accordingly has formulated norms which are anthropocentric. However, new approaches to environmental protection and conservation are required to be adopted which recognize the interconnectedness, interrelatedness and interdependency of the biotic and abiotic components of this earth.

Keywords: Anthropocentric, ecocentric, theocentric, earth jurisprudence, ecocentric democracy, environmental ethics.

Copyright (C) 2020 The Author(s): This is an open-access article distributed under the terms of the Creative Commons Attribution 4.0 International License (CC BY-NC 4.0) which permits unrestricted use, distribution, and reproduction in any medium for non-commercial use provided the original author and source are credited.

\section{INTRODUCTION}

The serendipitous fall out of COVID-19 pandemic has shaken various settled notions of the human society, nudging us to rethink our approach to those associated issues. One such area which has been captured within human experience during this trying time is the perceptible change in the quality of environment during widespread lockdown in various parts of the world [1-3]. For instance, Yamuna river, which flows in Delhi, India is one of the most polluted rivers by the time it reaches Delhi. However, the river has been reported to have improved its water quality during the lockdown, a feat which could not be achieved for many years in spite of the operation of the Yamuna Action Plan (YAP) [4] to clean the river. It has been noted that in about sixty days of lockdown, Yamuna river has cleaned itself using its own biological capacity [2].

What does it imply? It implies that humans are the culprit for the environmental pollution, that the environment has its own biological capacity to cleanse itself, if left to itself, that the steps which had been taken up to control environmental pollution are merely cosmetic affairs, real change in the quality of environment requires drastic steps which may call for high economic and social costs, that there is hope for reversing the trend in environmental pollution, provided there is collective will to do so, that responsible human behaviour and making conscious green choices will go a long way in improving the quality of environment, and last but not least, that the earth is better off without us - humans.

Accordingly, anthropocentric approach, with humans at the centre, towards protection of environment needs to be reviewed in order to make it more holistic and demolish the sense of false supremacy of humans over other species and the priority rights over the abiotic elements of nature. For instance, man is concerned with the survival of those species which are having perceptible connections with his own survival, while he puts in the backburner, the rest of those species, where he does not see or understand a live connection which intersects their web of life with that of his. It is also important to note that the perceptible species that has inter-linkage with man's survival depends on his own limited knowledge about nature and relations among its various components, which is directly proportional to his findings through use of 
scientific tools and research. But fact of the matter is that, the natural world exists and works in more ways that man has discovered. However, norms pertaining to the environment or its protection is determined by the restricted knowledge that man has.

Even if one take into consideration the precautionary principle in environmental law [5], it is imperative to have a 'suspicion' or some scientific findings which is awaiting to attain the standard of 'certainty' through further research. In the absence of these preliminary findings leading to raising of such suspicion or waiting for certainty, the precautionary principle cannot be brought to the fore and resorted to for the purpose of protecting the environment. Furthermore, it is also interesting to note that the focus of polluters pays principle or precautionary principles have been designed human-centric. When damages are quantified for polluting the environment, or human activities stalled on the basis of precautionary principle, the standpoint of both is human.

There is need to look at the different approaches to environmental protection. There has been difference of opinions with respect to the use of anthropocentric approach towards environmental protection. The first and foremost debate being valuation in nature are anthropocentric (human-centric) or ecocentric (non-human centric) $[6,7]$. There are two standpoints in this regard - one being that nature should be protected for its own sake. i.e. for its intrinsic value and the other being that nature must be saved to help ourselves, i.e. for its instrumental value [8]. Some writers argues in favour of anthropocentrism as something which is unavoidable and better than the traditional notion of intrinsic value which is ascribed with 'self-sufficiency, abstractness and justified in special ways' [9]. Alternative ideas are also placed in terms of reducing inequality to half, will bring about better conservation of nature rather than protecting half the earth from humanity [10].

Few others have discarded the anthropocentric approach or the ecocentric approach and focused on theocentric approach to explain man's relation with nature with the grounding on Catholic Christianity [11]. Madhu Khanna in her article analyses the nonmandatory approaches being used for environmental protection, surveys the existing theoretical literature and analyzed the economic efficiency of such approaches relative to mandatory approaches which is imposed by government. Gonzalez espouses for protection of entire ecosystem by taking a place-driven approach rather than program-based approach in the protection of environment [12].

The current study is focused on taking an approach which is neither anthropocentric nor ecocentric, in the way it is understood, but in a spiritual way, which is different from the theocentric approach talked about by Hoffman et al., [11]. The basis of this approach shall be on the Hindu culture's way of looking at nature and human-nature relationship. Though researches with similar orientation have been done in the past but hardly there are researches based on the Hindu culture and philosophy as the grounding for discourse in environmental protection and, therefore, it will be a knowledge addition in this field.

The methodology of the research shall be doctrinal, analytical research which will be based on already available secondary resources (books, articles, etc.) and primary sources (such as reports) on the research topic.

\section{Ancient Hindu Literature}

Environmental ethics was unknown in western philosophy until the mid 1970' [13]. However, in India, it has long been part of the Indian civilization and ethos since the vedic period, which has been tentatively suggested to be around 1500 - 500 BCE [14]. During the vedic period, ancient text on various issues have been written and can be classified into Vedas, Puranas, Upanishads (IGNCA) [15]. Veda comes from the Sanskrit root 'vid' which means 'to know' [16]. "'Veda' is also called 'Shruti' meaning what is heard, as opposed to the 'Smriti' composed by sages at a later stage recounting the content of the Vedic texts. This refers to the purely oral-aural method which was (and is) used for it" (IGNCA) [16]. These were later on written down and compiled into four vedas, viz. Rigveda, Samaveda, Yajurveda and Atharvaveda.

Rigveda also spelt as Rgveda which means in Sanskrit, 'The Knowledge of Verses' is the oldest and most voluminous of the sacred ancient books of Hinduism and has been composed about 1500 BCE (Encyclopedia Britannica) [17]. Rik is the name given to mantras, a 'sacred utterance that is considered to possess mystical and spiritual efficacy' (Encyclopedia Britannica) [18]. Yajurveda are the prayer books of Adhvaryu priest for performing sacrificial rituals [19]. Samaveda, means "Knowledge of Chants" which are chanted by Udagtr priest at the time of ceremonies of Soma sacrifice and procedures derived from it (IGNCA) [20]. The Upanishad were composed later around 1000500 BCE. They deal with philosophical knowledge. It has been said that - "In the whole world there is no study so beneficial and so elevating as that of the Upanishads... They are destined sooner or later to become the faith of the people [21]".

\section{Division of Ancient Hindu Literature}

"Broadly speaking the whole of the Vedic literature (Apara vidya) can be put into two categories:

1. The Vedas

2. The Vedangas 
'Veda' is a collective term indicating the four Vedas -

1. Rigveda,

2. Yajurveda,

3. Samaveda and

4. Atharvaveda.

On account of these four different Vedas, one often speaks of 'the Vedas' in the plural. The four Vedas consist of four different classes of literary works. To each of these classes belongs a greater or a smaller number of separate works, of which some have been preserved in their true form but also many lost in time. These four classes are:

1. Samhitas

2. Brahmanas

3. Aranyakas

4. Upanishads

Sometimes, the Aranyakas and Upanishads are treated as part of Samhitas/Brahmanas and not separately. The Vendangas consists of the six knowledge streams required for understanding of the Vedas. They are:

1. Shiksha

2. Kalpa

3. Vyakarana

4. Nirukta

5. Chanda, and

6. Jyotisha

In addition, each of the Veda consists of a secondary knowledge source (called upveda). They are:
1. For Rigveda-Ayurveda
2. For Yajurveda-Dhanurveda
3. For Samaveda-Gandharvaveda and
4. For Atharvaveda-Arthashastra" [16]

\section{Hinduism and Environmental ethics}

The veneration for the environment has been a basic foundation of Hindu society since its early days of Hindu civilization. In the important events of one's life such as birth, marriage, death etc. the rituals that are performed has close connection with nature. "Our ancient forefathers perceived God's presence around them through nature; they considered the natural forces which affected their lives as manifestations of the Supreme Being or the Brahman [22]".

\section{In Bhagwat Gita In Bhagwat Gita, Chapter 3 verse 10, it is stated that}

In the beginning of creation, Brahma created humankind along with duties, and said, "Prosper in the performance of these yajñas (sacrifices), for they shall bestow upon you all you wish to achieve [23]".

The commentary of this verse states that - "All the elements of nature are integral parts of the system of God's creation. All the parts of the system naturally draw from and give back to the whole [23]". This verse indicates that all component of nature, living or nonliving, big or small, are integral to the system created by God. Each component draws its sustenance from the system and each gives back to the system, and while doing so, it is performing the duty assigned to it in the system. For instance, an earthworm draws its food from the soil, which can be decaying roots, leaves, animal manure, small microorganism, etc. and in turn earthworm facilitates aeration of the soil, improve drainage, provide nitrogen rich casts and so on. In other words, it draws its sustenance from the soil system and gives back to the soil system by making it more fertile. Such relation is true for all elements of nature. Each component of the creation has its definite role to play and by doing so creates the balance in the web of life.

Another verse from the Rig-Veda states that "the sky is like father, the earth like mother and the space as their son. The universe consisting of the three is like a family and any kind of damage done to any one of the three throws the universe out of balance [24]". This verse shows that the ancient Hindus understood the correlation that exist among atmosphere, earth and the space/cosmos and the impact that each has over the other. Further, it has also been known to them that there is a fine balance amongst these which is necessary for their continued existence.

According to the Hindu philosophy, it is believed that every cosmic creation, including man, are made up of five elements, which is called pancha bhoota, viz. akashor firmament, vayu or air, agni, tejas or fire, apah or water, and prithvi. They believed that the five great elements (space, air, fire, water and earth) that constitute the environment are all derived from prakriti (i.e. nature), the primal energy and our human body is composed of these and related to these five elements, and connects each of the elements to one of the five senses [25]. The human nose is related to earth, tongue to water, eyes to fire, skin to air and ears to space. This bond between our senses and the elements is the foundation of our human relationship with the natural world. For Hinduism, nature and the environment are not outside us. They are an inseparable part of our existence and they constitute our very bodies [25]. According to the Hindu philosophy, the divine is not exterior to creation but expresses itself through natural phenomena. Thus, in the Mundaka Upanishad the divine is described as follows:

Fire is his head, his eyes are the moon and the sun; the regions of space are his ears, his voice the revealed Veda; the wind is his breath, his heart is the entire universe; the earth is his footstool, truly he is the inner soul of all [26].

The whole emphasis of the ancient Hindu scriptures is that human beings cannot separate themselves from natural surroundings and earth has the same relationship with man as the mother with her child 
[25].

This shows the commonality as well as interconnectedness of all elements of nature, both biotic and abiotic. In sloka 20, chapter 10 of Bhagavat Gita, Lord Krishna says -

"I am the ultimate consciousness in the heart of all creatures. I am the beginning, the middle and the very end of all beings".

This verse may be seen to indicate that the creator lies within the eternal soul of all His creations. All life forms that exist today are the products of evolution from the basic elements that existed in the primordial earth and ultimately it may collapse into one, similar to everything collapsing into a black hole in the universe. Though human species is at the top of the ladder of evolution, yet it is not seen as something apart from the earth and its multitudinous life forms. 'The Atharva Veda has the magnificent Hymn to the Earth which is redolent with ecological and environmental values' [26].

"Earth, my mother, set me securely with bliss in full accord with heaven, $\mathrm{O}$ wise one, uphold me in grace and splendour [26]".

It is remarkable that the people in Vedic times regarded nature and the environment in a holistic manner and revered each of its constituents and entities by carefully preserving them. "Do not harm the environment; do not harm the water and the flora; earth is my mother, I am her son; may the waters remain fresh, do not harm the waters... Tranquillity be to the atmosphere, to the earth, to the waters, to the crops and vegetation." This Vedic prayer invokes divine intervention to bless and protect the environment [27].

Bhagavat Gita considers "nature as one entity comprising of two components, i.e. Para, the consciousness part of the system and Apara, the physical part of it. The entire universe, including the earth, is considered to be created with the union of these two elements. The physical part of it is animated by the consciousness part and as such everything visible is considered to be manifestation of one Supreme whole [28]". Bhagwat Gita considers the "nature as the essence of human culture and the man devoid of nature is considered, an entity without soul' [28].

The Hindu philosophy does not endorse violence by human against lesser forms of life, but in fact highlights in the various incarnations of Lord Vishnu, how man has evolved from these forms and hence integrally linked to the whole creation. The Yajurveda lays down that "no person should kill animals helpful to all. Rather, by serving them, one should attain happiness" [26].
Hindus regard several trees as sacred; they are used in religious rituals (such as mango leaves, banyan leaves); trees such as banyan are considered to be abode of spirits and are not permitted to be cut down. Shrubs such as basil are not only considered as sacred but their medicinal value are known to them. Different types of animals, such as peacock, lion, bull, mouse is considered as mount of various deities. Cow, which is linked to human civilization and domesticated since time immemorial, is revered as mother. Indeed, reverence for plants and animals and to treat them compassionately is part of the Hindu philosophy.

\section{Environmental Ethics}

Environmental ethics has been defined as 'the study of ethical questions raised by human relationships with nonhuman environment' [29]. Brennan et al., has defined it as "the discipline in philosophy that studies the moral relationship of human beings to, and also the value and moral status of, the environment and its nonhuman contents" [30].

The various Hindu philosophies which are one of the oldest of the human civilizations and is reproduced above is replete with examples which shows that man is only a small part of the creations of nature. As man has evolved from lower life forms of nature over millions of years, he is just a part of them and therefore, not meant to dominate the lesser creations in the evolutionary chart. Further, as man is made up of the same five elements as any other creation in the cosmos, destroying or dis-balancing these elements will directly impact on man. It does not see the nature and its components as things which are meant to serve human needs. It acknowledges that humans draw its strength from nature and must show his reverence towards it.

The debate about the valuation of nature i.e. whether it has intrinsic value or instrumental value is not of much significance in Hindu philosophy, as it recognizes the interconnectedness of all creations, both living as well as non-living. As mentioned in the preceding section, all components of nature draw their sustenance from nature and they in turn has to contribute or play a role in maintaining the balance in the system.

Further, the Hindu concept of 'yoga', which is derived from the Sanskrit root 'Yuj', meaning 'to join' or 'to yoke' or 'to unite' [31] is aimed at uniting or experiencing the oneness with all creations; to dissolve the boundaries that separates ' $I$ ' from the rest, only then it is believed that ultimate blissfulness shall be experienced. There is no such dichotomy between nature and humans, humans are but part of nature itself; and if the balance in nature is destroyed by human actions then the impact will be suffered by all including humans. It is relevant to note that there has been a consistent increase in the number of emerging 
infectious disease events from wildlife-related zoonosis since 1940 and main cause of this increase is loss of biodiversity $[32,33]$. This also is an indication of the inter-relatedness of the creations in nature.

\section{Gaia Theory}

This interrelatedness among the biotic and abiotic communities, which was already understood in the ancient philosophy in India, is also the basis of gaia theory, a theory which developed in the West in 1970s. "The Gaia Theory posits that the organic and inorganic components of Planet Earth have evolved together as a single living, self-regulating system. It suggests that this living system has automatically controlled global temperature, atmospheric content, ocean salinity, and other factors, that maintains its own habitability. In a phrase, 'life maintains conditions suitable for its own survival' [34]." This theory suggests that 'living organisms on the planet interact with their surrounding inorganic environment to form a synergetic and selfregulating system that created, and now maintains, the climate and biochemical conditions that make life on Earth possible' [34].

Another intriguing finding is the ability of tree in a wood to communicate among themselves, support each other by sharing nutrients, warn others regarding an impending danger and regulate the local atmospheric condition in a way that trees that grow together in woods have a longer life than those that grow in isolation. In a way, trees growing in wood are said to be like colony of ants that support and communicate with each other with the help of network of fungi and microbes [35]. In another of his books, Wohlleben has espoused that the "natural world is a web of intricate connections, many of which go unnoticed by human. But it is these connections that maintain nature's finely balanced equilibrium [36]". He also stated that every entity in the nature, whether it is plant or animal, has its purpose and role in its ecosystem. This concept put forth under gaia theory, reverberates the same spirit that is embodied in the ancient Indian philosophy. It is indeed commendable that people of ancient India had such vast and in depth understanding of nature of relations among not only the living but also the living and the non-living.

\section{Earth Jurisprudence}

"Earth jurisprudence is a philosophy of law and human governance that is based on the fact that humans are only one part of a wider community of beings and that the welfare of each member of that community is dependent on the welfare of the Earth as a whole [37]." Members of the Harmony with Nature Knowledge Network believe that "..humanity, which is inextricably part of the community of life on Earth, cannot continue to override the laws that maintain the homeostatic balances of the Earth system [37]". This group is of the view that the current anthropocentric worldview has led to Earth being viewed as "a source of raw materials to be commercialised, exploited, modified, altered and privatised [37]." Such kind of approach has affected the health of the earth and the well-being of not just the humankind but also the components that make up the biosphere. They espouse for replacing the anthropocentric worldview with that of holistic system of governance and adopting 'ecocentric democracy' in decision making process [37].

\section{CONCLUSION}

As per ancient Hindu philosophy, everything in this universe operates as per the supreme law of the universe called 'Rita'. There does not seem to be a term in today's context which is equivalent to the term 'Rita'. The Earth Jurisprudence concept seems to go together to some extent with that of the supreme law of the universe. However, the Earth Jurisprudence concept has been popularised with an aim to implement the sustainable development goals in harmony with nature. But the moment sustainable development concept comes within the frame of discourse, so also the humancentric approach, after all sustainable development is meant to take care of the needs of the next generation of humans. So, it is of utmost importance that a new approach be developed while addressing the issue of protection of environment, keeping in view the ancient philosophy and the wisdom that has been gained through ages so that humans do not end up harming the whole cosmos in his attempt to amass wealth and privatise the wealth of the commons.

\section{REFERENCES}

1. Cleaner air during UK lockdown relieves asthma for millions. (2020, June 4). The Guardian. Available https://www.theguardian.com/environment/2020/j un/04/cleaner-air-during-uk-lockdown-relievesasthma-for-millions-lung-conditions-coronavirus (Accessed Nov. 10, 2020).

2. How River Yamuna Cleaned Itself In 60 Days of Coronavirus Lockdown. (2020, May 25). NDTV.com. Available at https://www.ndtv.com/india-news/coronaviruslockdown-yamuna-cleanest-in-30-years-asindustrial-dumping-halts-2234790 (accessed Nov. 10, 2020).

3. Delhi's cleaner air during lockdown may have helped produce more solar power: Study - ET EnergyWorld. (2020, June 23). www.ETEnergyworld.com. Available at https://energy.economictimes.indiatimes.com/new s/renewable/delhis-cleaner-air-during-lockdownmay-have-helped-produce-more-solar-powerstudy/76527264 (accessed Nov. 12, 2020).

4. Everything you need to know about the Yamuna Action Plan(YAP). (2017, Nov. 22). North India Statesman. Available at http://northindiastatesman.com/yamuna-actionplan/ (accessed Nov. 12, 2020). 
5. IUCN, 'Guidelines For Applying The Precautionary Principle' as approved by the $67^{\text {th }}$ meeting of the IUCN Council, 14-16 May 2007, p. 11. Available at https://www.iucn.org/sites/dev/files/import/downl oads/ln250507_ppguidelines.pdf (accessed Nov. 14, 2020)

6. Goodpaster, K. E. (1978). On being morally considerable. The Journal of Philosophy, 75(6), 308-325.

7. Taylor, P. W., \& Center for Environmental Philosophy, The University of North Texas. (1983). In Defense of Biocentrism. Environmental Ethics, 5(3), 237-243.

8. Tallis, H., \& Lubchenco, J. (2014). Working together: A call for inclusive conservation. Nature, 515(7525), 27-28.

9. Weston, A. (1985). Beyond Intrinsic Value: Pragmatism in Environmental Ethics. Environmental Ethics, 7(4):321-339.

10. Büscher, B., Fletcher, R., Brockington, D., Sandbrook, C., Adams, W. M., Campbell, L., ... \& Holmes, G. (2017). Half-Earth or Whole Earth? Radical ideas for conservation, and their implications. Oryx, 51(3), 407-410.

11. Hoffman, A. J., \& Sandelands, L. E. (2005). Getting Right with Nature: Anthropocentrism, Ecocentrism, and Theocentrism. Organization \& Environment, 18(2)141-162.

12. Gonzalez, O. J. (1996). Formulating an ecosystem approach to environmental protection. Environment Management, 20(5) 597-605.

13. III, Holmes Rolston. (2020). A New Environmental Ethics: The Next Millennium for Life on Earth. New York, NY: Routledge.

14. Cultural India. (n.d.) Vedic Age-Vedic Period, Vedic Civilization, Vedic Period Civilisation. Retrieved November 12, 2020, from https://www.culturalindia.net/indianhistory/ancient-india/vedic-civilization.html.

15. IGNCA. (n.d.) Rigveda|Vedic Heritage Portal. Retrieved November 14, 2020, from http://vedicheritage.gov.in/samhitas/rigveda/.

16. IGNCA. (n.d.). Introduction Vedic Heritage Portal. Retrieved November 14, 2020, from http://vedicheritage.gov.in/introduction/.

17. Rigveda Definition \& Facts. (2020). In Encyclopedia Britannica. Retrieved November 14, 2020, from https://www.britannica.com/topic/Rigveda.

18. Mantra. (2013). In Encyclopedia Britannica. Retrieved November 14, 2020, from https://www.britannica.com/topic/mantra

19. IGNCA. (n.d.). Yajurveda | Vedic Heritage Portal. Retrieved November 14, 2020, from http://vedicheritage.gov.in/samhitas/yajurveda/.

20. IGNCA. (n.d.). Samaveda | Vedic Heritage Portal. Retrieved November 14, 2020, from http://vedicheritage.gov.in/samhitas/samavedasamhitas/.
21. Varenne, J. (1989). Yoga and the Hindu Tradition (D. Coltman, Trans.) New Delhi, ND: Motilal Banarasidass.

22. Thyagarajan, Ramamoorthy. (n.d.) Vedas And Environment Protection. Retrieved November 14, 2020 , from https://www.academia.edu/24309112/VEDAS_A ND_ENVIRONMENT_PROTECTION

23. Mukundananda, S. (2014). Chapter 3, Verse $10-$ Bhagavad Gita, The Song of God - Swami Mukundananda. Retrieved November 14, 2020, from https://www.holy-bhagavadgita.org/chapter/3/verse/10.

24. Renugadevi, R. (2012). Environmental ethics in the Hindu Vedas and Puranas in India. African Journal of History and Culture, 4(1) 1-3.

25. Tanwar, D. R. (2016). Environment Conservation In Ancient India. IOSR Journal of Humanities and Social Sciences, 21(9) 01-04.

26. Alliance of Religions and Conservation. (1986). Faiths and ecology - The Hindu Declaration on Nature - Assisi 1986. Retrieved November 14, 2020, from http://www.arcworld.org/faiths.asp?pageID=18.

27. Vedic perspective on environment. (2009, June 30). The Times of India. Retrieved November 14, 2020 , from https://timesofindia.indiatimes.com/Vedicperspective-onenvironment/articleshow/4613346.cms.

28. Venkatasubramanian, S. G. (Aug. 2001). Emergence of environmental jurisprudence through judicial activism in India (Doctoral Dissertation). Available from INFLIBNET Centre database. (http://hdl.handle.net/10603/73994)

29. Palmer, C., Mcshane, K., \& Sandler, R. (Oct. 2014). Environmental Ethics. Annual Review of Environment and Resources, 39, 419-442.

30. Brennan, A., \& Lo, Y. S. (2020). Environmental Ethics. In Edward N. Zalta (ed.). The Stanford Encyclopedia of Philosophy. URL = $<$ https://plato.stanford.edu/archives/sum2020/entri es/ethics-environmental/>.

31. Basavaraddi, I. V. (Aril, 23, 2015). Yoga: Its Origin, History and Development. Retrieved November 14, 2020, from https://www.mea.gov.in/searchresult.htm?25096/Yoga:_su_origen,_historia_y_de sarrollo.

32. Keesing, F., Belden, L. K., Daszak, P., Dobson, A., Harvell, C. D., Holt, R. D., ... \& Myers, S. S. (2010). Impacts of biodiversity on the emergence and transmission of infectious diseases. Nature, 468(7324), 647-652.

33. Khetan, A. K. (Sep. 2020). COVID-19: Why Declining Biodiversity Puts Us at Greater Risk for Emerging Infectious Diseases, and What We Can Do. Journal of General Internal Medicine, 35(9) 2746-2747. 
34. Lovelock, J. (2003, Dec 18). Gaia: The living Earth. Nature, 426(6968) Art. no. 6968.

35. Popova, M. "n.d." The Secret Life of Trees: The Astonishing Science of What Trees Feel and How They Communicate', Brain Pickings. Retrieved o November 13, 2020, from https://www.brainpickings.org/2016/09/26/thehidden-life-of-trees-peter-wohlleben/.
36. Wohlleben, P. (2018). The Secret Network of Nature: The Delicate Balance of All Living Things (Billinghurst, J. Trans.), Germany, UK: Vintage.

37. Secretary General, UN in the United Nations General Assembly $71^{\text {st }}$ Session. (1 August 2016). Harmony with Nature. A/71/266 - E - A/71/266'. Retrieved November 14, 2020, from https://undocs.org/en/A/71/266. 